$$
\begin{aligned}
& \text { Example 1, } \frac{345}{215}=1.605 \\
& \text { Example 2, } \frac{150}{130}=1.154 \\
& \text { Example 3, } \frac{990}{390}=2.538 \\
& \text { Example 4, } \frac{1130}{390}=2.897
\end{aligned}
$$

\section{CALCULATION OF $\mathrm{H}$}

We have now all the necessary figures for the determination of $\mathrm{H}$.

Example $1, \mathrm{H}=2.25 \times 1.605=3.61$; example $2, \mathrm{H}=1.95$ $\times 1.154=2.25$; $\quad$ example $3, \quad \mathrm{H}=4.70 \times 2.538=11.93$; example $4, \mathrm{H}=5.68 \times 2.897=16.45$.

It may be pointed out that had we used the correct small triangles
A1 and A5 shown in fig. 5 instead of the simplified formula (1) the value of $\mathrm{H}$ for example 2 would have been $2 \cdot 16$.

We wish to express thanks to Professor A. M. Thomson and Professor F. E. Hytten for their help and advice during the preparation of this paper.

\section{References}

Ackerman, E., Rosevear, J. W., and McGuckin, W. F. (1964). Physics in Medicine and Biology, $9,202$.

Castro, A., Scott, J. P., Grettie, D. P., McFarlane, D., and Bailey, R. E. (1970). Diabetes, 19, 842

Ceresa, F., Serge, G., and Vitelli, A. (1962). Actualites Endocrinologiques, 3,

Fitzgeraid, M. G., and Keen, H. (1964). British Medical fournal, 1, 1568. Jarrett, R. J., and Graver, H. J. (1968). British Medical fournal, 2, 528. Lind, T., Van C. de Groot, H. A., Brown, G., and Cheyne, G. A., (1972). British Medical fournal, 3, 320

W.H.O. Expert Committee on Diabetes Mellitus (1965). World Health Organization. Technical Report Series, No. 310.

\title{
Effect of Carbohydrate Restriction in Obese Diabetics: Relationship of Control to Weight Loss
}

\author{
J. R. WALL， D. A. PYKE, W. G. OAKLEY
}

British Medical fournal, 1973, 1, 577-578

\section{Summary}

Two hundred newly diagnosed, fat diabetics were studied to determine whether control of the diabetes depended on loss of weight or on carbohydrate restriction alone. Satisfactory control was achieved by dietary treatment alone in $\mathbf{1 5 9}$ patients 30 required oral hypoglycaemic drugs and 11 were 18 of whom had actually gained weight. Of the remaining patients, 30 required oral hypoglycaemic drugs and 11 were still uncontrolled but not yet on other treatment.

The mean initial excess weight of all 200 patients was $28 \%$. Of those who remained uncontrolled on diet alone the mean initial excess weight $(31 \%)$ was slightly but not significantly greater than that of those who were controlled (27\%). Patients who were controlled lost slightly more weight than patients who were not, but their excess weight at the time of control was still $21 \%$.

We conclude that in $80 \%$ of obese diabetics control can be achieved by diet alone and that it is usually independent of weight loss.

\section{Introduction}

A large proportion of adult-onset diabetics are significantly overweight at the time of diagnosis (Pyke and Please, 1957). Although weight reduction is generally thought to be needed to achieve good diabetic control (Newburgh and Conn, 1939; Himsworth, 1949) we have noticed that many diabetics are controlled within days of beginning. carbohydrate restriction before significant weight reduction has occurred (Pyke, 1972).

We have therefore studied 200 obese adult-onset diabetics

Diabetic Department, King's College Hospital, London SE5 9RS

J. R. Wall, M.D., M.R.A.C.P., Clinical Assistant

D. A. Pyke, M.D., F.R.C.P., Physician

W. G. Oakley, M.D., F.R.C.P., Physician who were treated by diet alone to determine whether control of the diabetes depends on weight loss or on carbohydrate restriction alone.

\section{Patients and Methods}

The patients were newly diagnosed diabetics attending the outpatient clinic consecutively over the past three years, who were at least $10 \%$ above their expected weight* (mean excess $27.6 \%$ ). They had had no previous treatment. None of the patients was clinically dehydrated and there were no episodes of coma. There were 108 women and 92 men and their ages ranged from 23 to 90 , with over half in the 50-70 age group.

After the initial assessment and confirmation of the diagnosis the patients were started on a diet consisting of either carbohydrate restriction (usually to $100-150 \mathrm{~g}$ daily) or total restriction (usually to 1,000 calories). The diet was supervised at the first visit by the clinic dietician.

At each subsequent visit diabetic control was assessed from the presence and severity of symptoms, the degree of glycosuria, and the blood sugar levels. The patients were weighed under constant conditions and correlation was made between the control of the diabetes and the weight excess.

Final assessment was made either at the time of control or at the time that dietary management was thought to have failed and the patient was started on oral hypoglycaemic drugs. For this study we have not followed the patients after the time of first achieving control.

Diabetic control was defined as loss of symptoms, a blood sugar level under $160 \mathrm{mg} / 100 \mathrm{ml}$ about two hours after breakfast, and no more than a trace of glycosuria in one of two specimens (one from the previous night and one on the day of examination).

Blood glucose was estimated in whole blood by the ferricyanide method. Urine glucose was estimated with Clinitest.

- Taken from tables given in the New York Metropolitan Life Insurance Co. statistical bulletin November-December 1959. 


\section{Results}

The results are summarized in table $I$. Of the 200 patients 159 achieved good diabetic control on diet alone, in twothirds of cases by the second visit-that is, within 2 to 3 weeks. At the time of achieving control only 27 patients had reduced their weight to within $10 \%$ of that expected, while only two had returned to less than ideal weight. The other 130 patients were still $10 \%$ or more overweight, including 18 who had actually gained weight. The remaining 41 patients were not controlled by diet alone and required oral hypoglycaemic drugs (30 patients) or were still uncontrolled but not yet receiving further treatment (11 patients).

TABLE I-Diabetic Control and Weight Change of 200 Obese Diabetics Treated by Diet Alone. Mean Initial Excess Weight of all Patients $27 \cdot 6 \%$

\begin{tabular}{l|c|c|c|c|c}
\hline & $\begin{array}{c}\text { Mean } \\
\text { Excess } \\
\text { Weight } \\
\text { atients } \\
\text { at } \\
\text { Diag- } \\
\text { nosis }\end{array}$ & $\begin{array}{c}\text { Effect of } \\
\text { Treatment } \\
\text { on Mean } \\
\text { Weight }\end{array}$ & $\begin{array}{c}\text { Final* } \\
\text { Excess } \\
\text { Weight }\end{array}$ & $\begin{array}{c}\text { No. Still } \\
\text { Over 10\% } \\
\text { Above } \\
\text { Expected } \\
\text { Weight }\end{array}$ \\
\hline $\begin{array}{l}\text { Controlled by diet alone } \\
\text { Not controlled by diet }\end{array}$ & $\begin{array}{c}159 \\
41\end{array}$ & $\begin{array}{c}26 \cdot 8 \% \\
30 \cdot 6 \%\end{array}$ & $\begin{array}{l}\text { Lost } 5 \cdot 7 \% \\
\text { Lost 3.2\% }\end{array}$ & $\begin{array}{l}21 \cdot 1 \% \\
27 \cdot 4 \%\end{array}$ & $\begin{array}{c}130 \\
36\end{array}$ \\
\hline
\end{tabular}

*At time of achieving satisfactory control (1) or of being transferred to oral agents (2)

Only 34 of the 200 patients managed to return to within $10 \%$ of their expected weight and in only three cases did patients actually return to normal, or less than normal weight; all but five of the 34 were controlled by diet alone.

Patients who were subsequently controlled by diet alone were, at the time of diagnosis, $26.8 \%$ overweight compared to $30.6 \%$ for those who were not controlled, but the difference was not significant. Patients who were controlled on diet alone had lost a significant amount of weight (5.7\%) but the mean excess weight at the time of control was still $21 \cdot 1 \%$. Those who were not controlled on diet alone lost less $(3.2 \%)$ and were still $\mathbf{2 7 . 4} \%$ overweight when dietary treatment alone was judged to have failed and tablets were added. However, the difference between the amount of weight lost by the two groups is not significant. As can be seen from tables II and III, most patients did not lose an appreciable amount of weight. We did not start drug treatment until it was clear that diet alone had failed, which was usually after at least four months.

TABLE II-Weight Change of 159 Obese Adult-onset Diabetics Controlled by Carbohydrate Restriction Alone

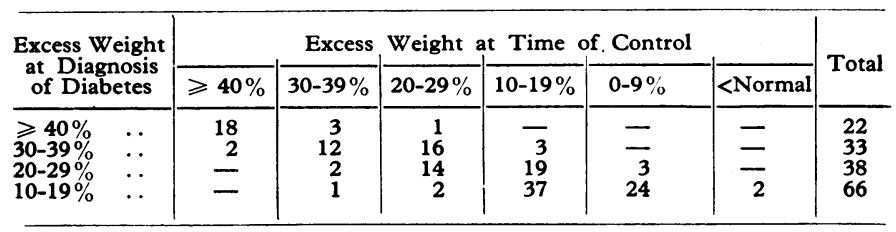

TABLE III-Weight Change of 30 Obese Adult-onset Diabetics Requiring Oral Hypoglycaemic Drugs

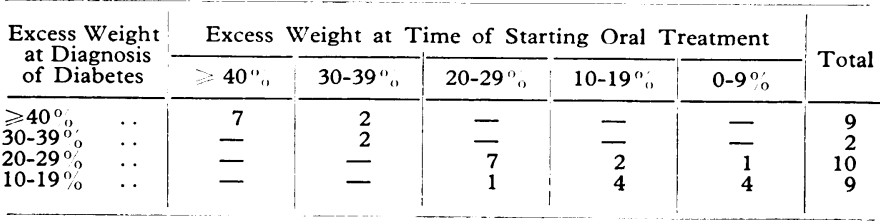

\section{Discussion}

From this study it is apparent that $80 \%$ of obese adult-onset diabetics can be controlled by dietary restriction alone, and that in two-thirds of cases control is achieved without appreciable weight reduction.

We do not know whether our patients actually adhered to the diets we prescribed for them: we think it likely that they reduced their carbohydrate intake somewhat, since so many of them showed an improvement in the state of their diabetes and no other treatment was given. It may well be that cessation of glucose loss in the urine was a contributory factor; our point is that, however it was achieved, control of diabetes was attained before, or without, significant weight loss.

If the basic abnormality in obese adult-onset diabetics is an increased but relatively insufficient circulating insulin level to maintain normal blood sugar in the presence of increased glucose turnover, carbohydrate restriction, with or without total calorie restriction, should be associated with a fall in insulin levels and amelioration of the diabetes (Karam et al., 1963; Perley and Kipnis, 1966). Plasma insulin levels were not measured in this study, but Grey and Kipnis (1971) have shown that when obese patients are put on a carbohydrate-restricted diet the fasting plasma insulin level falls and rises again when a high carbohydrate, isocaloric diet is substituted, without any change in weight. Further, Rudnick and Taylor (1965) reported improvement in carbohydrate tolerance and increased insulin responses to glucose in obese and non-obese diabetics after four months on a carbohydrate-restricted diet.

We conclude that control of diabetes in obese patients who respond to diet alone is due to carbohydrate restriction rather than to weight loss.

\section{References}

Grey, N. and Kipnis, D. M. (1971). New England fournal of Medicine,

Himsworth, H. P. (1949). Lancet, 1, 465.

Karam, J. H., Grodsky, G. M., and Forsham, P. H. (1963). Diabetes, 12, 197.

Newburgh, L H., and Conn, J. W. (1939). fournal of the American Mcdical Association, 112, 7 .

Perley, M., and Kipnis, D. M. (1966). Diabetes, 11, 867

Pyke, D. A. (1972). Acta Diabetologica Latina, 9, Suppl. No. 1, p. 511.

Pyke, D. A., and Please, N. W. (1957). Fournal of Endocrinology, 15, xxvi.

Pyke, D. A., and Please, N. W. (1957). Fournal of Endocrinology, 15, xxvi. 1225 . 